\title{
EL TERCER GOBIERNO PERONISTA Y LAS VILLAS MISERIA DE LA CIUDAD DE BUENOS AIRES (1973-1976)
}

\author{
ALICIA ZICCARDI
}

\section{Introducción}

El presente trabajo es parte de una investigación sobre las relaciones que entablaron los pobladores de las villas miseria de la Capital Federal con las instituciones del Estado, en el marco de la sociedad global y en diferentes coyunturas. El período que consideraremos aquí es el del último gobierno peronista (1973-1976), tiempo en el que los villeros atravesaron por una etapa de alto desarrollo organizativo, en una permanente búsqueda por obtener respuestas del gobierno popular a sus postergadas demandas.

Ya desde la década anterior, este sector popular urbano constituía !n conjunto social definido que, si bien desde el punto de vista cuantitativo era incomparablemente menor al de otras ciudades latinoamericanas, había sabido desarrollar diferentes tipos de agrupaciones sociales. ${ }^{1}$ Desde éstas, los villeros se habían tornado legítimos interlocutores de diferentes agencias estatales; supieron enfrentar los más elaborados planes de erradicación; fueron introduciendo la problemática de sus precarias condiciones de vida en las causas económicas y sociales que generaban su presencia en el medio urbano; mejoraron a través del trabajo colectivo los más graves problemas de su vida cotidiana; en fin, fueron formando una identidad propia e intentaron su articulación con las fuerzas políticas populares. Trabajadores no calificados, particularmente obreros de la industria de la construcción y trabajadoras de servicios domésticos remunerados, eran las actividades ocupacionales que predominaban en el interior de las villas miseria y que explicaban, finalmente, las causas de la constitución de estos barrios populares urbanos. Su inestabilidad laboral, su bajo grado de calificación, sus limitados ingresos, la indocumentación de los migran-

${ }^{1}$ En 1975 la Comisión Municipal de la Vivienda estimaba que la población villera de la Capital Federal era de 179322 habitantes. 
tes de países limítrofes, impedían que esta parcela de la fuerza de trabajo lograse acceder a una vivienda digna y a bienes y servicios colectivos indispensables.

A partir de esa precaria agrupación territorial, las villas fueron transformándose en verdaderos barrios urbanos, en los cuales las condiciones de habitabilidad mejoraban a medida que la organización de los villeros se iba consolidado. En todo este proceso de lucha por la sobrevivencia en el medio urbano, las organizaciones sociales gestadas en su territorio fueron uno de los principales vehículos para lograr la satisfacción de las demandas más inmediatas. Clubes deportivos y culturales, asociaciones de madres, juntas y comisiones vecinales, agrupamientos de varias villas miseria, ofrecían paliativos para enfrentar colectivamente ese conjunto de condiciones sociales adversas. Pero más aún, desde este ordenamiento natural y de su organización sectorial, los habitantes de villas miseria habían conseguido cierto grado de legitimidad en diferentes períodos históricos y desatado fuerte oposición a las políticas gubernamentales que intentaron desconocerlos o subordinarlos a su propio proyecto de erradicación. ${ }^{2}$

La llegada del gobierno peronista fue celebrada por los villeros y por todo el pueblo argentino como el inicio de una nueva etapa. Las expectativas de que sus principales reivindicaciones finalmente encontraran satisfacción, crecieron intensamente en el seno de las organizaciones villeras. Pero el camino atravesado por este sector social, en los años del gobierno peronista, estuvo signado por sucesivas frustraciones. La articulación de las organizaciones villeras con la línea política de la Juventud Peronista y su inevitable enfrentamiento con los sectores más reaccionarios del Movimiento Peronista -enquistados en el ministerio de Bienestar Social-llevaron a que una vez más este conjunto social fuese objeto de un tratamiento discriminatorio y autoritario por parte de las instituciones del Estado.

El ritmo y la intensidad de la lucha de esos años, tiende a ocultar la dinámica propia que adquirieron diferentes frentes del campo popular. $^{3}$ Los villeros, ciertamente, ocupaban un lugar periférico en el acontecer nacional. Sin embargo, sus prácticas y sus luchas se intro-

${ }^{2}$ En 1967 se elaboró una acabada ley y se puso en marcha un complejo plan de erradicación de villas miseria. Sobre la respuesta de los pobladores de las villas frente a una alternativa que suponía peores condiciones de vida de las que poseían originalmente véase: A. Ziccardi (1977); O. Yujnovsky (1982).

3 El período que estrictamente se considerará en este trabajo es el comprendido entre los años 1973 y 1975 , puesto que a partir de la segunda mitad de este último año la política de vivienda hacia las villas ya se había desarticulado y las organizaciones villeras comenzaron a desmembrarse. 
dujeron en el espacio político donde se enfrentaron los sectores del movimiento peronista que sustentaban estrategias polarizadas.

Investigar este comportamiento social obliga a hacer referencia, de un lado, a las instituciones del Estado que tenían facultad gubernamental para abordar el problema; en lo fundamental el Ministerio de Bienestar Social (MBS) y la Comisión Municipal de la Vivienda (CMV). A ello deberá agregarse la importancia que adquirió la vivienda popular en el Plan Trienal elaborado e implementado por el Ministerio de Economia y las vinculaciones que se entablaron entre los habitantes de las villas y la Universidad Nacional de Buenos Aires. Del otro, se deben analizar las articulaciones entre el movimiento villero y diferentes actores de la sociedad civil: la Juventud Peronista (JP), los Sacerdotes para el Tercer Mundo y los grupos de profesionales peronistas. Evidentemente, no se pretende establecer líneas divisorias - por lo demás difusas o inexistentes en el interior de la dinámica social - sino simplemente organizar la información obtenida de manera que la misma pueda ser trascendida en explicaciones globales que permitan obtener alguna luz para explicar la trágica derrota popular argentina.

\section{El Gobierno Peronista}

El 11 de marzo de 1973 el pueblo argentino consagró en las urnas el retorno y el triunfo del peronismo. El Frente Justicialista de Liberación (FREJULI), obteniendo el 49.5 por ciento del electorado, anuló el intento del régimen militar de condicionar la apertura democrática. ${ }^{4}$ La fórmula Cámpora-Solano Lima, con el aval de las fuerzas sociales mayoritarias, se impuso en medio de un clima de incontenible movilización popular. La realización del acto eleccionario fue tan sólo el corolario de la opción planteada por un gobierno militar deslegitimado socialmente frente al ritmo e intensidad de la lucha social y a un viejo líder que condujo a su Movimiento hacia una salida democrática.

Desde fines de los setenta, los trabajadores habían comenzado a cuestionar desde sus centros de trabajo las políticas económicas que afectaban constantemente su salario real, las fórmulas de exclusión

${ }^{4}$ El balotaje como forma de garantizar que el peronismo tuviese que realizar arreglos con otras fuerzas políticas y con los militares, quedó de lado, ante el abrumador triunfo del FREJULI. 
política o participación subordinada a que pretendía someterlos el proyecto militar y la capacidad de sus dirigentes gremiales para adjudicarse la representación del movimiento sindical. Al mismo tiempo, y ante la ausencia de canales de participación, importantes capas de la pequeña burguesía generaban nuevas formas de politización pugnando, principalmente desde el interior del movimiento peronista, por instrumentar una estrategia popular que obligara a la definitiva retirada militar (véase: De Riz, 1981; Landi, 1971: 89-127; Saltalamacchia, 1980: 10-12). Los sectores populares en general, pero también las fracciones de la pequeña y mediana burguesía nativa, mostraban su reprobación al intento militar de reestructurar la sociedad argentina a fin de intorducirla definitivamente en el orden económico internacional organizado por el capital transnacional.

Así, en la Argentina se fueron gestando nuevos actores sociales que, desde diferentes espacios y con distintas posibilidades de actuación, exigían participación en el rumbo de la vida nacional.

Perón, desde su exilio, incorporó a su proyecto político estas demandas y otorgó legitimidad a nuevas fuerzas dentro del movimiento peronista. A partir de 1972, la Juventud Peronista fue la fuerza que hegemonizó el proceso de movilización y organización popular que caracterizó al período preelectoral. Los barrios populares urbanos y en medida decreciente, la Universidad y los centros de trabajo, fueron los lugares donde reclutó, rápidamente, sus adeptos, constituyendo en la Tendencia Revolucionaria del Peronismo. ${ }^{5}$

El 25 de mayo de 1973, el doctor Hector J. Cámpora asumió la presidencia de la República en medio de un clima de fuerte efervescencia popular. Las bases de sustentación social de este fugaz gobierno fueron justamente la JP, el sindicalismo combativo y algunos sectores de la burocracia política del movimiento. Landi (1979) ha señalado que el nuevo gobierno no representaba realmente la correlación de fuerzas entonces existente. Ciertamente, aún cuando el gabinete formado durante el período presidencial de Cámpora fue el que, salvo excepciones, acompañó a Perón en su tercera presidencia, desde su inicio el gobierno peronista fue expresión de la intensa lucha que por la definición del proyecto protagonizaron las distintas corrientes del Movimiento y de la sociedad argentina. El retorno de Juan Perón, el 20 de junio de 1973, lejos de constituir una fiesta nacional, se convirtió en una masacre política. Grupos armados de la derecha peronis-

5 En junio de 1972, un miembro de la Juventud Peronista ingresó al Consejo Superior del Movimiento Justicialista. Al mismo tiempo, Perón legitimaba la existencia de las organizaciones armadas como formaciones especiales para la lucha en la coyuntura. 
ta impidieron que la movilización popular, organizada principalmente por la JP, pudiera expresarse frente al líder. El saldo de muerte que acompañó el regreso a los barrios, las villas, los centros de trabajo, marcó muy probablemente el comportamiento político que las organizaciones populares peronistas asumieron en adelante. La violencia hacía su aparición en el gobierno popular, augurando, en cierta medida, la derrota de los sectores de la izquierda del peronismo.

A pesar de ello, Perón intentó en adelante poner orden. La renuncia de Cámpora le permitió redefinir los lineamientos de su gobierno. Sus discursos y acciones se orientaron entonces a redefinir gradualmente los espacios políticos que el conductor adjudicaría a las diferentes fuerzas sociales. Su proyecto de "democracia integral" basado en la "comunidad organizada", pretendía fincar la estabilidad del país en la participación de la Confederación General del Trabajo (CGT), y la Confederación General de Empresarios (CGE), el partido Unión Cívica Radical y las Fuerzas Armadas.

La Argentina había mostado, de manera contundente, que la más estructurada política económica sucumbía ante la lucha social desatada por los sectores sociales afectados en sus intereses. Por ello, Perón subordinó la posibilidad del Plan Trienal a la firma del Acta de Compromiso Social (El Pacto Social), mediante la cual el capital y el trabajo (la CGE y la CGT) se comprometían a respetar los términos de la nueva política económica. Esta intervención política sobre el ciclo productivo y el conflicto que el mismo encierra, sentó los primeros pasos hacia un crecimiento económico basado en promover y diversificar las exportaciones y expandir la inversión pública. Esto permitió que, pese a la resistencia de la iniciativa privada a invertir, se produjera una efectiva elevación de las tasas de crecimiento global de la economía durante los años 1973 y 1974.

Sin embargo, las demandas salariales no se hicieron esperar, siendo presentadas ante un sector empresarial que no estaba dispuesto a sacrificar su tasa de ganancia. Esta situación, sumada al déficit del sector público, llevó a que en los primeros meses de 1974 quedaran claros los límites sociales de los acuerdos pactados. El resultado económico no podía ser otro que la vuelta a un proceso inflacionario provocado principalmente por el traslado de los aumentos salariales a los precios. Perón ya había demostrado su intención de disciplinar a los sectores que no estuvieran de acuerdo con el rumbo que el líder imprimía al movimiento. 6 Sin embargo, no consiguió alinear a las demás

6 El 1 de mayo de 1974, la Juventud Peronista concurrió a la concentración popular en la Plaza de Mayo con las consignas: "que pasa, qué pasa, qué pasa gene. ral, está lleno de gorilas el gobierno popular", "asamblea popular, no queremos 
fuerzas económicas y políticas que veían desvanecerse nuevamente la esperanza de desarrollar un capitalismo autónomo, con crecimiento económico y reforma social. La muerte del presidente y la incapacidad política de su sucesora no hicieron más que acelerar el fracaso del proyecto nacional peronista.

Durante el gobierno de Isabel Perón se produjo la caída del ministro de Economía, José Gelbard, y se sucedieron una serie de programas económicos que contaron, alternativa o conjuntamente, con el apoyo del lópezrreguismo y la burocracia sindical. ${ }^{7}$ El clima de lucha corporativa que desataron los gremialistas y la violencia política generalizada que permeaba la sociedad argentina, precipitaron al peronismo a una crisis que no sólo afectaba su articulación en tanto movimiento social, sino implicaba la caducidad de una alternativa de desarrollo. ${ }^{8}$

\section{El gobierno nacional y la política de vivienda popular}

El Plan Trienal del ministro de Economía José Gelbard asignaba a la política de vivienda un rol estratégico en el proceso de recuperación de la economía. A nivel nacional, el organismo gubernamental que poseía la responsabilidad de asumir la puesta en marcha de una política de vivienda popular era el Ministerio de Bienestar Social. Este Ministerio, como en épocas anteriores, constituía uno de los resortes

carnaval"; "si Evita viviera sería montonera". El general Perón, enfurecido, se dirigió a la JP calificando a sus miembros de "imberbes", "idiotas útiles", "mercenarios al servicio del extranjero". La Juventud abandonó espontáneamente la plaza. El 24 de mayo, la rama juvenil quedó excluida del Consejo Superior Justicialista. Cfr. L. De Riz (1981: 111).

${ }^{7}$ En octubre de 1974 fue reemplazado José Gelbard y se hace cargo el doctor Gómez Morales en un intento de peronizar el gabinete, puesto que él mismo había sido ministro de Economía del segundo gobierno peronista (1952-55). En junio de 1975 asumió dicho ministerio Celestino Rodrigo, representante del lópezrreguismo, quien fue derrocado por la lucha sindical y reemplazado por el doctor Antonio Cafiero, quien contaba con el apoyo de sindicalistas y políticos peronistas.

8 Portantiero sostiene: "El golpe militar de 1976 -por cierto, como todos los que tuvieron lugar en el cono sur en esa época- no fue el resultado de un complot diabólico de la CIA sino el producto de la crisis histórica de una alternativa de desarrollo. En Argentina la forma que asumió esa crisis fue la de la desarticulación del peronismo: el fin de un tipo de pacto estatal que solamente en el interior de un preciso contexto pudo transformarse en un punto de referencia para una coalición de distintos sectores, cuando el patrón de consumo popular coincidió con la dinámica del desarrollo capitalista. Fue mucho más la presión corporativa de los sindicatos sobre la tasa de ganancia que el desborde guerrillero lo que descalabró el proyecto". Véase J.C. Portantiero (1980: 12-14). 
más importantes de la gestión gubernamental. El titular de esa cartera fue, desde el inicio del gobierno peronista hasta pocos meses antes de su derrocamiento, José López Rega, representante de uno de los grupos de derecha del Movimiento.

El que un pequeño grupo carente de base social obtuviera una instancia gubernamental cuya competencia era la distribución de bienes y servicios a los sectores populares, abría la posibilidad de que éste ganara adeptos y, en consecuencia, espacio político dentro y fuera del peronismo. Sin embargo, en las villas, como veremos, la actuación ministerial pretenderá desplegar una acción tendiente a subordinar a las organizaciones de los pobladores, a fin de legitimar un proyecto de erradicación abiertamente opuesto a las demandadas que las mismas sustentaban desde hacía más de una década.

El Pacto Social -que soportaba al Plan Trienal- fue presentado por Gelbard como la condición que permitiría al gobierno "socializar los beneficios del progreso, la vivienda, la educación y la salud". Este acuerdo se constituiría en el esquema director de una política económica cuyos objetivos generales eran: 1) implementar una política salarial que permitiese una justa distribución del ingreso, 2) eliminar la marginalidad social mediante la acción efectiva del Estado en materia de vivienda, educación, salud y asistencia social, 3) absorber en forma total y absoluta la desocupación y el subempleo, 4) mejorar la asignación regional del ingreso y 5 ) terminar con el descontrolado proceso inflacionario y fuga de capitales (véase Gelbard, 1973: 6). Si bien una de las metas que condicionaba el plan era lograr una efectiva austeridad en el gasto público, la construcción masiva de viviendas por medio de la acción estatal encontraba justificación económica y social en el interior del proyecto. Ésta era una actividad productiva que estimulaba la inversión privada generando al mismo tiempo un número importante de nuevos empleos. Por medio del financiamiento público se ejercería una redistribución del ingreso al permitir el acceso a este bien necesario a los sectores sociales que, por su limitada o inexistente capacidad de ahorro, no pudieran participar del merdado privado. Otro objetivo adicional no menos importante, era reducir el marcado déficit habitacional que afectaba a grandes contingentes de trabajadores.

En el programa económico de Gelbard no podían estar ausentes, ni la tradición de participación estatal que en materia de vivienda habían desarrollado los gobiernos peronistas anteriores, ni el compromiso que adquirió Cámpora en el inicio de su gestión. ${ }^{9}$ El MBS conta-

9 Sobre la acción del sector público durante el primero y segundo gobiernos peronistas, véase: Schteingart y Brodie (1974: 235-286). Sobre los lineamientos generales del programa peronista de vivienda de 1973, véase: Cámpora (1973). 
ría con los recursos financieros necesarios para estimular la industria de la construcción que, entonces, presentaba cierto grado de estancamiento y un elevado nivel de capacidad ociosa. A la vez, podría garantizarse que mediante adecuadas formas de pago se favoreciese a los sectores sociales de ingresos medios y bajos. ${ }^{10}$ Concretamente, en el Acta de Compromiso Nacional se estipulaba que:

el Banco Central [...] proveerá que el 80 por ciento del crédito bancario para vivienda, sea destinado al financiamiento de unidades de hasta 70 metros cuadrados de superficie; su repago se realizará a tasas de interés de fomento y con cuotas que no superen el 20 por ciento del ingreso de cada solicitante. ${ }^{11}$

La Subsecretaría de Vivienda y Urbanismo del MBS y el Banco Hipotecario Nacional (BHN), en función conjunta, tendrían inicialmente a su cargo la formulación y desarrollo de un programa cuya efectivización requeriría de la participación de institutos provinciales, direcciones municipales de vivienda, etcétera. Los recursos con los que contaban para ello serían los provenientes del Fondo Nacional de la Vivienda y Pronósticos Deportivos, recursos propios de BHN, y el redescuento de su cartera hipotecaria. ${ }^{12}$ Así, a mediados de 1973, el MBS - autodenominado el "Ministerio del Pueblo"- daba a conocer, a través de una masiva campaña publicitaria, su programa de vivienda popular. Como luego veremos, los pobladores de las villas miseria se informaron del mismo por los medios de comunicación, no obstante las relaciones que se habían entablado ya entre este aparato gubernamental y las organizaciones villeras. Bajo los eslogan: "Hacer una casa no es juego de niños. Vamos a construir 500000 viviendas" y "Un techo para cada uno en el país de todos", el ingeniero Juan Carlos Basile, subsecretario de Vivienda y Urbanismo, pondría en marcha un ambicioso programa habitacional. Los tres planes que lo conformaban eran los siguientes:

-Plan Alborada: destinado a los residentes de las villas de emergen-

10

La cifra de 500000 viviendas fue anunciada sin que se diera cuenta con base en qué estimaciones el Estado evaluaba que podía emprender una acción de tal magnitud. Posteriormente, el Plan Trienal especificaba que la meta era 815000 viviendas, a ser construidas durante esos tres años; 510000 viviendas por medio de la acción estatai y el resto por medio de la iniciativa privada. Véase: Ministerio de Hacienda y Finanzas (1974).

11 Acta de Compromiso Nacional (1973).

12 El Fondo Nacional de la Vivienda (FONAVI) se formaba con el aporte del $1.5 \%$ por concepto de gravamen sobre la venta de ganado vacuno a faenar para todo destino y un aporte del $2.5 \%$ sobre las remuneraciones a cargo del empleador, fuese éste el Estado o los factores. Sobre la importancia y destino de estos recursos, véase: O. Yujnovsky (1982). 
cia, rancheros, personas que vivían en pensiones o en viviendas precarias y para todos los que no encontraran vivienda. También se incluían en este plan los residentes de áreas fronterizas. Las viviendas a ofrecer serían conjuntos habitacionales definitivos, en unidades indiviudales o colectivas con equipamiento comunitario.

-Plan Eva Perón: consistente en préstamos individuales para la construcción de viviendas familiares propias, bajo la exigencia de tener en propiedad un terreno urbanizado de 200 metros cuadrados como mínimo.

-Plan 17 de octubre: destinado a otorgar préstamos para la construcción de viviendas a los sindicatos, cooperativas, asociaciones sin fines de lucro, ahorristas del Banco Nacional, mutualistas, entidades comerciales (Ministerio de Bienestar Social, Ministerio del Pueblo, 1973).

Desde los enunciados de estos planes se puede inferir hacia cuáles clientelas orientaba su acción el MBS. También se desprende la posible disputa entre los sectores sociales destinatarios de los recursos.

La población de las villas miseria quedaba incorporada al Plan Alborada, pero compartiendo sus beneficios con el grueso de los sectores sociales de menores recursos que padecían condiciones de vida deterioradas y precarias. Estos recursos eran comparativamente menores que los destinados a satisfacer la demanda de los trabajadores asalariados. ${ }^{13}$

Pero lo fundamental no era el tipo de vivienda ni la cantidad de casas que el MBS estaba dispuesto a otorgar a la población de las villas miseria. La política de construcción de viviendas nuevas, aunque fuesen definitivas, se contraponía a la principal reivindicación de los trabajadores de las villas: la expropiación de las tierras que ocupaban y el mejoramiento de sus viviendas o la construcción de nuevas viviendas en sus localizaciones originales.

No puede atribuirse al desconocimiento de la lucha villera la decisión de planear la erradicación de las villas de la Capital Federal. Por ese entonces, sus pobladores habían entablado relaciones con las agencias estatales exponiéndoles propuestas habitacionales alternativas. Por otra parte, el mismo Ministerio, en su publicación, declaraba inicialmente que se:

construirian nuevas viviendas donde se encontraban los asentamientos precarios, reservándose la erradicación cuando las dimensiones, ubicación y características del terreno no lo permitieran (Ministerio de Bienestar Social, Ministerio del Pueblo, 1973: 7).

${ }^{13}$ Las metas planteadas asignaban al Plan Alborada 188700 viviendas, al 17 de octubre, 214000 viviendas; y al Eva Perón, 107000 viviendas. Cfr. Sociedad Central de Arquitectos (1976). 
Sin embargo, puesto en marcha el Plan Alborada, se desconocieron las demandas de los pobladores, intentándose subordinarlos mediante la acción de equipos de "trabajo social". Ciertamente, el advenimiento del peronismo había alimentado en las organizaciones villeras expectativas favorables a la satisfacción de sus demandas. Pero el gobierno nacional encargaba el tratamiento de la cuestión al sector oficial que mayores distancias ideológico-políticas poseía con el campo popular en su conjunto y, particularmente, con los habitantes de las villas miseria.

La Universidad de Buenos Aires, particulamente la Facultad de Arquitectura y Urbanismo intentó tener alguna ingerencia en los programas de habitación popular en general y en los destinados a los villeros en especial. Sin embargo, al igual que la CMV, no consiguió incidir en las decisiones ministeriales. Mientras el MBS estaba en manos de la derecha peronista, la Universidad de Buenos Aires fue encargada al doctor Rodolfo Puiggrós, representante de las corrientes político-culturales de izquierda del Movimiento.

La política que elaboró la Universidad para insertarse en el proceso del gobierno peronista planteaba la articulación efectiva entre los profesionales universitarios y la sociedad nacional con el objeto de servir a los intereses populares.

Más allá de las dificultades que presentó su puesta en práctica, ${ }^{14}$ esta política se apoyaba en un hecho cierto: la vivienda popular era ya un núcleo movilizador de profesionales (médicos, abogados, arquitectos, asistentes sociales, etcétera) que desde distintas disciplinas venía trabajando dentro del Movimeinto Peronista en los denominados Equipos Político-técnicos de la $\mathrm{JP}^{15}$ y las villas miseria habían sido uno de los lugares donde esta acción se había desplegado con cierto éxito. $\mathrm{El}$ asesoramiento a los extranjeros residentes, la instalación de dispensarios médicos que ofrecían remedios y prestación clínica gratuita, el apoyo técnico en la construcción de viviendas, obras de infraestructura o planes alternativos a los proyectos estatales, habían sido problemas que estos profesionales habían atendido en algunas villas de la Capital Federal. Que la "Universidad Nacional y Popular" pudiera extender estas pequeñas experiencias y generar apoyos masivamente, así como ofrecer alternativas habitacionales a partir del desarrollo de la investigación, eran metas legítimas hacia las cuales orientar las tareas

14 Un balance sobre la Universidad durante el último gobierno peronista puede verse en: Puiggrós, A. (1979a: 11-12) y Puiggrós, A. (1979b: 16-19).

15 A este agrupamiento se sumaban otros como el Consejo Tecrológico Peronista que había elaborado una propuesta de vivienda para el gobierno. Véase: Movimiento Nacional Justicialista, Consejo Tecnológico (1973). 
de docentes y alumnos. En diciembre de 1973, la Universidad convocó al Primer Congreso Nacional de la Vivienda Popular, organizado por la Facultad de Arquitectura y Urbanismo. El objetivo de este encuentro fue abrir un diálogo entre las entidades oficiales, universitarias, empresariales y vecinales que actuaban en el campo de la vivienda popular. En lo particular, se trataba de presentar propuestas y consideraciones en torno al plan de 500000 viviendas anunciado por el MBS. Los trabajos presentados en sus seis mesas expresaban el apoyo a los lineamientos programáticos específicos del Plan Trienal, ofrecían recomendaciones en torno al problema de la vivienda de alquiler y discusiones en torno al papel de la Universidad ante el problema habitacional. ${ }^{16}$ No obstante, la política de vivienda del MBS en nada consideró las sugerencias y aportes ofrecidos a través de materiales de amplia divulgación y que fueron difundidos sintéticamente en la prensa capitalina.

Ahora bien, como sostiene Yujnovsky (1982), si se considera globalmente la acción habitacional del gobierno peronista, puede advertirse que:

se construyó en promedio menos de un cuarto de la cantidad anual propuesta por el Plan Trienal. De todos modos ello implicó un incremento cierto de la actividad del sector público y una participación mayor de los sectores de menores recursos en el mercado de la vivienda.

Pero difícilmente puede afirmarse que la población villera fue destinataria de un monto importante de recursos. Más bien, el programa habitacional supuso cierto grado de equilibrio entre los intereses de la política económica global (CGE), el lópezrreguismo (MBC) y la burocracia sindical (CGT). Las organizaciones villeras, en cambio, no constituían una fuerza social que necesitara ser incorporada al proyecto para grantizar su éxito. Por ello el MBS optó por una relación autoritaria, anulando toda posibilidad de que los importantes recursos estatales con que contaba se orientaran a mejorar las condiciones de vida de estos trabajadores urbanos. ${ }^{17}$ La exclusión de los villeros en el proceso de toma de decisiones fue la tónica de la política ministerial.

También pueden introducirse consideraciones críticas a esta política desde una perspectiva estrictamente técnica. Profesionales y asocia-

16 Véanse los informes de las comisiones y documentos presentados en el Primer Congreso Nacional de la Vivienda Popular, Buenos Aires, 20 al 23 de diciembre de 1973.

17 José Gelbard en una carta dirigida al presidente de la CGE en ocasión de su renuncia al cargo de Ministro decía: "No hay variables económicas de corto plazo para medir lo que puede denominarse la 'eliminación de la marginalidad social', pero los programas de erradicación de villas, que Economía financió haciendo verdaderos esfuerzos [...] deben comportarse como elementos coadyuvantes", en Controversia, año II, núm. 5, México, marzo de 1980, pp. 10-17. 
ciones dedicados al problema de la vivienda popular señalaron fuertes limitaciones de la acción buernamental: 1) Mientras los sectores sociales de menores ingresos aportaba el 79.9 por ciento del déficit habitacional existente, solamente se les asignaba el 32 de los recursos disponibles. Esto era parte de una política que daba prioridad a la recuperación de la inversión más que a la distribución del ingreso. 2) $\mathrm{Si}$ bien ninguno de los planes propuestos cumplió las metas que se trazaron (es decir, no se desarrollaron en el ritmo previsto), el Plan Alborada fue el que presentó un mayor índice de atraso. El déficit habitacional, tres años después, se había incrementado más allá de lo previsto. 3) Las reglamentaciones y normas de financiamiento del Plan Alborada no fueron suficientes para instrumentar una política efectiva dirigida a los sectores de menores ingresos. Se presentaron procesos especulativos y excesos que encarecieron artificialmente los costos, a lo que se sumó la insuficiencia de los equipamientos que poseían los conjuntos habitacionales (véase: Sociedad Central de Arquitectos, 1976). El MBS pretendió combinar, en la gestión gubernamental, tecnocracia y autoritarismo. Para ello centralizó las decisiones, excluyó a otras agencias estatales que poseían ya experiencia en el tratamiento de esta cuestión social e intentó subordinar sin éxito a las organizaciones de los residentes de las villas que se opusieron abiertamente a la concreción de sus planes.

\section{El gobierno municipal y las villas miseria}

El retorno a la legalidad democrática hizo posible que el gobierno municipal, en 1973, reactivara su estructura institucional. Es decir, si bien el Intendente de la comuna de Buenos Aires era un cargo designado por el Presidente de la República, existía también el Concejo Deliberante, órgano elegido mediante votación directa por los habitantes de la ciudad, el cual podía canalizar las demandas de sus representantes. ${ }^{18} \mathrm{El}$ organismo municipal encargado del problema de las villas miseria, desde mediados de los sesenta, era la Comisión Municipal de la Vivienda. Estas institución tuvo como función específica implementar el Plan de Erradicación de Villas de Emergencia (PEVE) durante el régimen militar, en el contexto de la Capital Federal. Sin embargo, en su interior, los jóvenes técnicos que componían su perso-

18 El Concejo Deliberante de la Ciudad de Buenos Aires, había cumplido un importante papel durante su último período de actuación (1963-1966), el cual había permitido la introducción de un conjunto de mejoras en las villas (Ziccardi, 1979). 
nal comenzaron a sumarse al proceso de politización generalizada que experimentaban las capas medias del país. A ello se sumó el hecho de que el ultimo Intendente del gobierno militar, pretendiendo transformar su imagen eficientista e intentando articular un proyecto político no inmediato sino de largo plazo, condedió la realización de una experiencia piloto: la construcción de viviendas en terrenos próximos a una pequeña villa (la núm. 7), que se llevó a cabo con la participación de los pobladores en todas las ctapas del proyecto (véase: Varios autores, 1982: 10-29). La demostración de que los núcleos habitacionales transitorios hacia los cuales la CMV había trasladado a los habitantes de las villas erradicadas no constituían mejora alguna en relación a las condiciones de vida originales de los trabajadores y tendían a convertirse en una vivienda deteriorada y definitiva provocó un proceso de crítica entre sus cuadros técnicos y asistentes sociales. Esto permitió un mayor acercamiento entre el personal de la CMV y las organizaciones villeras, y comenzó a prestarse atención a las demandas que presentaban los pobladores sobre mejoramiento de las condiciones de vida en los asentamientos existentes. Es decir, la CMV se distanció de los lineamientos establecidos por el PEVE.

A diferencia de las demás instituciones gubernamentales, la CMV había acumulado y procesado una rica información y experiencia sobre la situación que prevalecía en las villas. En 1970, la CMV evaluaba que de las 34 villas miseria que habían llegado a existir, sólo quedaban 29; las restantes habían sido erradicadas por el PEVE. La población villera estaba conformada por 24220 familias, un total de 104420 personas. Pero lo fundamental en estos asentamientos no era la precariedad de sus condiciones habitacionales (las cuales eran compartidas por otros tipos de vivienda: conventillos, tugurios en general, urbanizaciones precarias en terrenos propios en el área del Gran Buenos Aires) sino su carácter de "intrusos" en relación a las tierras ocupadas. La magnitud del problema había alentado expectativas institucionales de hallar soluciones por la vía de ofrecer alternativas habitacionales. Sin embargo, estudios realizados por la CMV en 1971 indicaban que, al dividir a la población villera de acuerdo a nueve estratos de ingresos, el 44.17 por ciento que conformaban los tres más bajos se hallaba en una situación de abierto desahorro (Comisión Municipal de la Vivienda, 1971). Al comparar esto con las cuotas de amortización de los programas en curso y agregarle los gastos que debían pagar los usuarios por concepto de impuestos y tasas de servicios, se percibía que el porcentaje de familias sin solución habitacional estatal se elevaba a un 67.42 por ciento del total. En el otro extremo, tan sólo el 0.48 por ciento de las familias tenía capacidad de acceso a cualquiera de los programas de la CMV aún con los plazos más cortos de amorti- 
zación. Los estratos intermedios, según su composición familiar e ingresos, se encontraban en distintas condiciones de accesibilidad a los programas, en términos de cuotas y plazos de amortización. Evidentemente, el que la gran mayoría se hallara fuera de las posibilidades de acceder a una vivienda financiada por el gobierno municipal exigía pensar en otra respuesta institucional: mejorar los barrios existentes.

Por otra parte, la CMV comenzaba a tener recursos económicos muy limitados. Hacia 1972, cuando debía iniciarse la segunda etapa de su programa habitacional en el Parque Alte. Brown, el Banco Interamericano de Desarrollo no renovó su crédito. La CMV entonces carecía de recursos propios para ejercer una acción autónoma frente a otras instituciones del Estado. Ello contribuyó a que se desplegara una política tendiente al mejoramiento de las villas miseria, para lo cual había alcanzado una gran capacidad y experiencia técnicas. Así, se produjo un acercamiento con algunas comisiones vecinales, que plantearon sus demandas y encontraron eco en la agencia municipal.

Al formarse el Frente Villero de Liberación en plena campaña electoral, el intendente de la comuna, contador Saturnino Montero Ruiz, decidió reconocer a la organización como representación de las villas de Buenos Aires y otorgar un fondo de 500 millones de pesos destinados a realizar las mejoras que los pobladores consideraran prioritarias. Se inició un diálogo abierto, que se tranformaría luego en participación de los villeros en la agencia municipal. Debe pensarse que, al mismo tiempo, se producía en la CMV un proceso de organización sindical y movilización política generalizadas entre su personal técnico y administrativo. Con posterioridad al triunfo del FREJULI, se formalizó la participación de los villeros a través de la creación de una Oficina de Villas en la cual trabajaban tres pobladores remunerados en la administración y tres en el depósito de materiales.

En julio de 1973, como resultado de los conflictos que se sucedieron en la institución municipal, se fijó el compromiso de establecer definitivamente la participación de las organizaciones sociales villeras, para ese entonces nucleadas en el Movimiento Villero Peronista (MVP). La forma de participación de los pobladores en la gestión municipal fueron las mesas de trabajo, experiencia que ya se había puesto en práctica. Estas mesas abarcaban temas particulares y generales y estaban constituidas por representantes de los organismo del Estado competentes en los distintos problemas tratados (Obras Sanitarias de la Nación, Servicios Eléctricos del Gran Buenos Aires, etcétera). ${ }^{19}$

${ }^{19}$ Véase: Comisión Municipal de la Vivienda (1973a y 1973b). Ambos trabajos fueron presentados en el Primer Congreso Nacional de la Vivienda Popular, Buenos Aires, del 20 al 23 de diciembre de 1973. 
Esta política de reconocimiento de la legitimidad de los pobladores para decidir sobre los proyectos que se dirigían a modificar sus condiciones de vida, se oponía abiertamente a la que efectivamente desplegó el MBS. Al mismo tiempo, la escasez de recursos financieros y el desinterés del titular de la municipalidad por asumir la función de promoción de vivienda popular que le correspondía a la CMV en el ámbito de la Capital Federal, llevaron a que se fueran desatando conflictos en el interior de la institución. El apoyo que podían ofrecer los representantes sindicales y la Juventud Trabajadora Peronista (JTP) -agrupación formada por los técnicos y profesionales de la institución- a la labor efectuada por el Movimiento Villero Peronista, no fue suficiente para vehiculizar un proyecto de gestión popular.

A principios de 1974, utilizando la ley de prescindibilidad aplicable a los trabajadores del Estado, se destituyó de sus cargos técnicos y administrativos a los representantes del personal que conformaban un cuerpo de delegados. La movilización de los empleados de la institución y una huelga de hambre por parte de los doce despedidos, llevó a que las autoridades municipales los reincorporaran. Sin embargo, en medio de una coyuntura totalmente desfavorable para la izquierda peronista, el saldo de la lucha era francamente negativo. Los representantes no regresaron a sus lugares de trabajo originales sino que pasaron a ocupar distintas funciones, en otras reparticiones de la municipalidad. Esto coincidía con un proceso de desarticulación del MVP a causa del fracaso de su lucha por lograr participación en el aparato gubernamental del gobierno peronista.

\section{La organización social de los residentes de las villas miseria}

Sumándose a la movilización que protagonizó el pueblo argentino durante la campaña electoral del FREJULI, los pobladores de las villas miseria comenzaron a participar activamente en el conjunto de tareas políticas que desarrollaba el Movimiento Peronista. Se trataba de garantizar el cumplimiento del acto electoral y, con posterioridad, la entrega del gobierno y la consolidación del proyecto popular sustentado por la fórmula vencedora en los comicios. El período, que en realidad podría circunscribirse al comprendido entre los años 1973 1975, constituye para la historia de este movimiento social una de las experiencias más ricas de profundización y expansión de su capacidad organizativa, aún cuando el mismo no escape a la derrota que sufrieron el conjunto de las fuerzas populares. La participación del Frente Villero de Liberación y del Movimiento Villero Peronista como organi- 
zaciones sectoriales que nucleaban al conjunto de las villas del país, fueron indicadores del salto cualitativo que experimentó la organización villera en la coyuntura.

\section{a) El Frente Villero de Liberación Nacional}

En febrero de 1973, cuando ya la Federación de Villas y Barrios de Emergencia había perdido representatividad en el interior de los barrios, un grupo de dirigentes decidió crear el Frente Villero de Liberación Nacional (FVLN). ${ }^{20}$ Esta organización sectorial se formó mediante una amplia convocatoria, a fin de discutir la situación particular de los trabajadores que vivían en las villas y las condiciones que habían llevado al debilitamiento de la organización sectorial de los pobladores. Se trataba de construir un nuevo movimiento que sumase su acción a la movilización política desplegada por el conjunto del pueblo argentino. Pero, en cierta medida, se pretendía resguardar la organización villera del partidismo. Como se vio, el Frente obtuvo rápidamente el reconocimiento del Intendente de la MBA, quien ofreció un monto significativo de recursos económicos y técnicos para introducir las mejoras que los villeros consideraran prioritarias. El FVLN, por su parte, solicitó que se creara una organización institucional permanente dedicada a atender en forma exclusiva los reclamos villeros. Debía servir a la vez de intermediaria entre los demás organismos municipales y/o nacionales y en ella tendrían cabida funcionarios municipales y representantes de las villas y barrios obreros, en igual número o en mayoría de éstos. Éste fue el antecedente de las mesas de trabajo que se crearon con posterioridad en la CMV.

Las principales reivindicaciones que levantaba el FVLN en su Estatuto de Constitución del 17 de febrero de 1973, eran:

1) La mejora de los barrios y la resolución de las necesidades más urgentes en las villas, en los núcleos habitacionales transitorios y en los barrios definitivos construidos por organismos gubernamentales, con la participación de residentes de estas viviendas.

2) La expropiación de tierras ocupadas por las villas.

3) La suspensión de todo desalojo.

4) La derogación de la ley 17605.

5) La construcción de viviendas definitivas en los mismos lugares o lugares próximos a los que se hallan ubidadas las villas, cuyas cuotas

$20 \mathrm{La}$ Federación de Villas y Barrios de Emergencia había sido una organización capaz de guardar cierto grado de autonomía respecto a los lineamientos políticos generales que emanaban del PCA. Sin embargo, su identificación con esta estrategia política impidió que se sumara a la misma el grueso de los villeros que, como la mayor parte del pueblo, se adherían al peronismo. Esta organización sectorial actuó en las villas miseria de 1958 a 1972. 
no superaran el 10 por ciento del salario y los servicios el 5 por ciento. Sin discriminaciones entre solteros, casados, concubinos, argentinos o extranjeros, tengan o no documentos.

A medida que el FVLN se iba consolidando, se profundizaba su estructura organizativa, designándose un mayor número de representantes por cada villa. En un principio se constituyó solamente con representantes de 10 comisiones vecinales de los tres mayores conglomerados villeros de la ciudad de Buenos Aires: Retiro, Lugano y Bajo Flores. Luego, paulatinamente se fueron sumando las demás villas. La definición del FVLN por el peronismo no fue demorada, aun cuando inicialmente se lo hiciese de manera muy general. Es decir, se trató de no adherir expresamente a ninguna de sus corrientes internas. Los Sacerdotes para el Tercer Mundo constituían un importante apoyo para las organizaciones villeras y al constituirse el Frente, los medios de comunicación atribuyeron rápidamente la paternidad del mismo a este grupo de religiosos. Tampoco escaparon a estas apreciaciones los profesionales de la CMV que, desde sus lugares de trabajo, conseguían efectivizar el cumplimiento del compromiso asumido por la Comuna en relación a las mejoras. ${ }^{21}$

Durante el acto eleccionario y con mayor intensidad con posterioridad, el FVLN fue tomando una serie de posiciones políticas claras, tanto en torno al peronismo como a sus corrientes internas. Así, se nombró al general Perón presidente honorario del mismo, ${ }^{22}$ se enviaron cartas al bloque de diputados del FREJULI solicitando la libertad de "los patriotas detenidos por luchar por la Liberación de nuestra Patria y por entender que bajo el Gobierno Peronista no puede haber presos políticos", ${ }^{23}$ se optó por modificar su denominación por la del Frente Villero Peronista de Liberación (FVPL). El 19 y 20 de mayo de 1973, el FVPL llamó a la realización del Primer Congresode Liberación "Eva Perón". Recuperando la tradición de la Federación de Villas, se intentaba el acercamiento de los villeros a las organizaciones sindicales, por lo cual el encuentro se realizó en el Sindicato del Calzado. Participaron en el mismo 15 villas, lo cual constituía un número menor de lo esperado.

La ausencia de más representantes se debió a que, pocos días antes, la JP decidió agrupar a un conjunto de representantes villeros y, con el apoyo de Sacerdotes para el Tercer Mundo, lanzaron un nuevo

21 Un periódico de Buenos Aires decía: "El Frente Villero de Liberación es orientado por el cura peronista Carlos Mujica y su creación fue anunciada en la Capilla Cristo Obrero". Clarin, Buenos Aires, 4 de marzo de 1973.

22 Cominicado de Prensa del FVLN, Buenos Aires. 10 de abril de 1973.

23 Carta del FVLN al Bloque de diputados del FREJULI, Buenos Aires, 3 de mayo de 1973. 
agrupamiento: el Movimiento Villero Peronista. En cierta medida, la explicación de porqué se creó otra organización sectorial debe buscarse en la tendencia prevalenciente en el peronismo de izquierda de crear frentes de masas controlados en última instancia por una conducción vertical de la que emanaban las líneas políticas globales y particulares y a la que debía ajustarse cualquier lucha social reivindicativa. Esto llevaba a que, en lugar de intentar una política de alianzas con otras organizaciones populares de la sociedad civil, se tendiera a la autosuficiencia política y con ello al abandono de las demandas que requerían de apoyos externos para su satisfacción. A pesar de ello, el Congreso contó con el apoyo explícito de dirigentes peronistas de izquierda, así como también de diputados de la juventud. Pero los representantes que participaron del mismo eran exclusivamente villeros, actuando los demás como observadores. Se formaron cinco mesas de trabajo en las cuales se analizaron temas tales como: politica económica, vivienda, educación, salud, problemas laborales. Algunas resoluciones del congreso fueron: la expropiación de todas las tierras donde hubiese villas, la creación de una empresa nacional de construcción, la participación de todos los villeros en todos los planes de reconstrucción de villas y poner fin a la represión en las villas. $\mathrm{Al}$ mismo tiempo el Frente expresó su posición ante el gobierno electo sosteniendo:

El Frente Villero Peronista de Liberación empeñará todo su esfuerzo en la Reconstrucción Nacional considerándola como un proceso dinámico de lucha, movilización y apoyo a nuestro gobierno peronista, impulsando el cumplimiento y profundización de las pautas programáticas del FREJULI, atendiendo especialmente las propuestas surgidas del seno de la clase trabajadora para la construcción del socialismo nacional. Trasladando las instancias de decisión política de los cuerpos burocráticos del Estado hacia las bases polares. ${ }^{24}$

La presencia de dirigentes que habían sabido resguardar la autonomía de las organizaciones villeras frente al Estado, llevaba a que nuevamente los trabajadores de las villas supiesen entablar un diálogo con las instituciones estatales, sin por ello abandonar las premisas de participación que habían orientado su acción permanente. En esta dirección, el FVPL, solicitó una entrevista al ministro de Bienestar Social, invitándolo a una reunión en la villa de Lugano. En esa ocasión, López Rega se dirigió a los villeros y les dijo:

"trataremos de que la Comisión del Frente Villero nos ayude a solucionar inmediatamente -ahora, no mañana-los problemas

24 Comunicado de prensa del FVPL, Buenos Aires, 21 de mayo de 1973. 
más imperiosos que existen en las villas. Nuestros asesores y nuestro subsecretario mantienen las puertas abiertas para conocer y dar solución a los problemas de los villeros pero esto debe hacerse con un concepto peronista y coordinadamente. Convoco a la Comision del Frente Villero para que venga a instalarse en el Ministerio, para que sean los impulsores de las soluciones. ${ }^{25}$

El Frente aceptó el ofrecimiento, en la creencia de que con ello se legitimaba su participación en la gestión gubernamental. También impulsó una reunión con las más altas autoridades del MBS y las tres agrupaciones villeras que existían entonces: el FVPL, el MVP e Intervillas. $^{26}$ La misma actitud tomaba frente a la CMV y la Intendencia Municipal, a fin de que se diese continuidad a las obras de mejoramiento iniciadas.

Por otra parte, la aparición del MVP, lejos de ser evaluada como negativa, llevaba a estos dirigentes, portadores de gran experiencia política, a intentar la unificación. Así en su órgano de difusión expresaban: El FVPL hace un llamado a los compañeros del MVP y a los Sacerdotes para el Tercer Mundo que han participado, a deponer discrepancias estériles y enfrentamientos artificiales. El 11 de marzo el pueblo peronista dio un ejemplo de lucha dejando de lado lo secundario y derrotando la dictadura militar. ¿Qué sentido tiene dividir fuerzas? Invitamos nuevamente a los compañeros del MVP al diálogo franco y a la unidad de los villeros. Pero al mismo tiempo dejaban claro: La mayoría de nosotros somos de la Unidad Básica y de la JP, de afuera recibimos aportes, ayuda, pero no órdenes. Las órdenes las damos nosotros en la villa. ${ }^{27}$

El anuncio del MBS del plan de viviendas populares, cambió totalmente la posición delas dos organizaciones villeras. Como se vio, el FVPL no fue consultado sobre el Plan Alborada, lo cual evidenciaba que los asesores gubernamentales intentaban utilizar esta agrupación tan sólo para legitimar su política. Ésta, en el mejor de los casos, podría tornarse clientelística, pero estaba lejos de orientarse hacia el reconocimiento de las reivindicaciones y la autonomía que reclamaban las organizaciones villeras. A partir de allí, el Frente Villero y el Movimiento Villero Peronista constituyeron una Comisión Unificadora, la cual tomó como principal interlocutor de sus reclamos a la CMV. Un mes después se fusionaron definitivamente.

25 Frente Villero, órgano de difusión del FVPL, Buenos Aires, junio de 1973.

26 Idem. Intervillas era una pequeña organización liderada por dirigentes que no formaban parte de los otros dos agrupamientos y que pretendían acercase al ministro de Bienestar Social.

27 Idem. 


\section{b) El Movimiento Villero Peronista}

Como ya se dijo, el 17 de mayo de 1973 otro grupo de villeros con apoyo de los Sacerdotes del Tercer Mundo y de las Unidades Básicas de la JP organizó el Movimiento Villero Peronista (MVP).

Desde su inicio, se definió como una agrupación política de los villeros para participar en el Gobierno Justicialista de Reconstrucción Nacional, que llevaría a la imposición del socialismo nacional. Los dirigentes villeros que lo impulsaban contaban con reconocimiento y prestigio, lo cual permitía retomar las reivindicaciones de etapas anteriores con la esperanza de alcanzar su satisfacción. Se trataba de exigir la participación popular en la gestión de los organismos gubernamentales, de profundizar la organización política villera y de introducir las tareas colectivas de mejoras o las propuestas de viviendas en un proyecto político global.

El principal y quizá único recurso con que contaba la JP eran sus cuadros políticos, lo que permitió que, al poco tiempo de constituido el MVP, desplegaran un conjunto de tareas de mejoramiento en las villas. Estas acciones fructificaron en un acelerado reclutamiento de adeptos.

Las campañas de alfabetización de adultos, de vacunación e instalación de dispensarios que atendían gratuitamente y suministraban remedios, campamentos infantiles de recreación para niños villeros, organización de brigadas de trabajo para el cavado de zanjas, pavimentación de calles, asesoría legal a los extranjeros para obtener su documentación, reparto gratuito de leche, fueron, entre otras, las acciones a través de las cuales el MVP se constituyó en una organización villera de nivel nacional. Por otra parte, la capacidad de convocatoria que poseía la JP entre intelectuales y técnicos hacía que las villas de Buenos Aires aceptaran, por primera vez, la presencia masiva de "los de afuera" y confiaran en los apoyos que podían ofrecerles para mejorar sus condiciones de vida. Rápidamente el MVP creció y comenzó a impulsar la participación de sus representantes ante las mesas de trabajo de la CMV. A pesar de haber asistido a reuniones en el MBS, esta agrupación, dados sus vínculos con la JP, fue la primera fuerza en enfrentarse al ministro de Bienestar Social. Por ello, cuando el FVL fue claramente excluido de la política gubernamental y se apartó del ministerio, se pudo concretar la Comisión Unificadora Villera Peronista. Esta Comisión actuó principalmente en el interior de la CMV y le cupo a la misma, junto con los trabajadores de dicha institución, defender la propia existencia de las mesas de trabajo amenazadas de ser disueltas. Al poco tiempo, el FVP y el MVP se fusionaron definitivamente, optando por utilizar en adelante la denominación de esta última organización y adhiriéndose a su estrategia política. 
Durante la campaña electoral que llevaría al general Perón a su tercera presidencia, el MVP desplegó un conjunto de actividades de propagandización y movilización política que contribuyeron aún más a su crecimiento. En poco tiempo, el MVP adquirió el carácter de agrupación nacional, celebrando su Primer Congreso Nacional en la ciudad de Santa Fe el 20 y 21 de octubre de 1973. Meses después, la noticia de que las villas de la "Zona Eva Perón" iban a ser erradicadas, marcaba definitivamente cuál era la política que el Estado estaba dispuesto a implementar hacia las villas: la erradicación.

La realización de Primer Congreso Nacional de Vivienda Popular, como vimos, había ofrecido bases para que los pobladores participasen del proceso de diseño y construcción de las viviendas. La Universidad, así como también institutos e instituciones de algunos gobiernos provinciales y municipales, estaban dispuestos a trabajar para la concreción de estas propuestas. Que el MBS no diese cabida a los reclamos villeros, no hacía más que reafirmar el acierto de la JP al identificar al ministro de Bienestar Social como representante de los intereses más reaccionarios introducidos en cl aparato estatal.

Durante la realización del Segundo Congreso Nacional Villero, el MVP se definió como una organización política reivindicativa y no ya como un movimiento de masas. Su función específica era enunciada como la de: elevar el nivel de conciencia de los compañeros villeros para encarar la lucha política desde un proyecto político peronista revolucionario (Movimiento Villero Peronista, s/f). El MVP orientaría su acción junto con la de otros sectores de la clase trabajadora para que el Movimiento Peronista fuese realmente una herramienta de liberación. En realidad, la evaluación de la que partían era que el Pacto Social no representaba, en los hechos, al Frente de Liberación Nacional y que para efectivizar éste se requería que el mismo fuese hegemonizado por los trabajadores. La manera como el MVP se insertaría en el Frente era creando cooperativas y empresas populares, y participando en las mesas de trabajo. Estas propuestas específicas requerían obviamente toda una reestructuración de las organizaciones naturales que habían desarrollado los villeros con anterioridad. Pero debe decirse que no fueron pocas las villas en las cuales se intentaron poner en marcha estas propuestas, aún cuando su efectivización requería una modificación sustancial de las relaciones con el aparato gubernamental. Hasta ese momento, salvo las experiencias llevadas a cabo puntualmente en la CMV y en otros organismos provinciales, no existía ninguna participación activa de los villeros en la toma de decisiones políticas. Sin embargo, el MVP sostenía: 
[...] consideramos que el General no está cercado. La posibilidad inmediata de una salida realmente popular es la apertura de los sectores mayoritarios (villeros y toda la clase trabajadora) (Movimiento Villero Peronista, s/f).

Es decir, el puebio no estaba participando, pero debía movilizarse para lograrlo. Para ello, el MVP proponía:

1) Solicitar al gobierno nacional el reconocimiento oficial del MVP como organización politica de los villeros; 2) pedir la oficialización de las mesas de trabajo ya existentes y la creación de otras en todas las áreas del gobierno, a nivel nacional, provincial o municipal $y$, concretamente, recomendar la creación de esas mismas mesas en el Ministerio de Bienestar Social, con el fin de que los villeros podamos ejercer en una forma un control en los proyectos y ejecuciones de ese Ministerio; 3) solicitar en nombre de este Congreso una entrevista con el General Perón para interiorizarlo de la marcha y objetivos que hacen a nuestro movimiento (Movimiento Villero Peronista, $\mathrm{s} / \mathrm{f}$ ).

Ninguno de estos objetivos fue logrado y el MBS comenzó a efectivizar sus propósitos de traslado de los residentes de la Villa 31 a conjuntos habitacionales en la periferia de la ciudad. ${ }^{28}$ Perón se encargó de aclarar cuál era la posición del gobierno nacional ante la cuestión villera. El 23 de enero de 1974, la Junta de Delegados de la Villa 31 y el MVP consiguieron entrevistarse con el General, quien luego de expresar su opinión sobre los problemas generales que enfrentaba el urbanismo actual (espacios verdes, carreteras, esmog, etcétera), como consecuencia del rápido crecimiento de las ciudades, declaraba que las villas debían ser erradicadas:

Nuestro deseo es erradicar totalmente las villas de emergencia, especialmente por los chicos, porque son peligrosas. Es ahi donde surgen las epidemias por falta de servicios y de higiene natural, porque están apiñados uno encima del otro y porque están en zonas de contaminación, que es otra cosa que hay que ir eliminando [...] Muchos de ustedes que son jóvenes quizá no lo aprecien pero cuando tengan hijos entonces empezarán a pensar. El Estado, cuando construye, debe pensarlo todo $[\ldots]^{29}$

$\mathrm{Al}$ mismo tiempo, evidenciaba que los villeros estaban transitando por el camino de la "ilegalidad" sosteniendo:

También tenemos interés en solucionar pronto el problema de la

28 Sobre las luchas que protagonizaron durante más de una década los villeros de la zona Retiro o Villa 31 para evitar la erradicación, elaborando diferentes propuestas alternativas a los sucesivos proyectos gubernamentales, véase: Pastrana (1980: 124-142).

29 Periódico La Nación, Buenos Aires, 24 de enero de 1974. 
documentación. A nosotros nos pagan por cumplir la ley y para hacerla cumplir.Ustedes están la mayoría fuera de la ley, pero no por culpa de ustedes, sino por la incuria de las autoridades que deberian haber ido regularizando esta situación a medida que iban entrando al país. Acá puede entrar cualquiera. Nosotros queremos poner orden. Si no se van a producir toda clase de dificultades en el futuro. Estar en una situación irregular es un peligro permanente, entonces ¿qué cuesta regularizarla y tener ladocumentación correspondiente? Asi estarán de derecho, no de hecho, porque estar fuera de la ley es siempre cuestión peligrosa. Estando dentro de la ley no hay peligro para nadie, fuera de la ley se está en el filo de la navaja [... ]. ${ }^{30}$ Los villeros habían recurrido al líder para exponerle un proyecto alternativo según el cual la autopista costera podía realizarse sin abandonar la posibilidad de que construyesen sus nuevas viviendas en el mismo lugar. Frente a ésto el General expresaba que el proyecto del MBS contaba con su aval, con lo cual estaba marcando límites muy precisos al comportamiento futuro de los villeros.

Las alternativas eran, en realidad, pocas. Había sido el MBS y no los villeros quien había descartado la posibilidad de diálogo y participación. La erradicación es siempre el momento en el cual las relaciones entre villeros e instituciones del Estado se tensan en mayor grado. Las opciones del MVP y la villa de Retiro en particular se reducían a que, o bien los dirigentes abandonaban definitivamente las reivindicaciones que durante muchos años habían sostenido con su lucha, o bien trataban de dar continuidad a la misma aún durante el gobierno peronista. Aunque el momento político ya no era propicio para impulsar la movilización popular, los villeros de la Zona Eva Perón, optaron por mantener cierta fidelidad a sus ideas y proyectos originales. ${ }^{31} \mathrm{En}$ el seno del MVP existían pocas posibilidades de sostener una línea política que desembocara en un enfrentamiento con el gobierno popular. Así, las disputas ideológicas sobre el rumbo que debía tomar el Movimiento Villero se libraron en el seno mismo de su conducción. Lo que estaba en juego, en última instancia, era continuar con la JP y la línea que emanaba de su organización político-militar, o distanciar al movimiento de esta posición. Los representantes del MVP de la Capi-

\section{Idem.}

31 El desalojo de la 31 comenzaba el 19 de febrero del 74 con un acto simbólico en el que la Vicepresidenta de la nación hizo entrega de un "departamento del Edificio 38, complejo habitacional de Villa Celina, Partido de la Matanza, a la Sra. [...] quien recibió también la correspondiente documentación de la vivienda"... "La medida fue recibida con sumo desagrado por parte de los villeros quienes alegan que tal disposición atenta contra su propia unidad y obstaculiza sus posibilidades de trabajo". Periódico El Mundo, Buenos Aires, 24 de febrero de 1974. 
tal, con una única excepción, reafirmaron su adhesión a dicha estrategia política. Algunos de los Sacerdotes para el Tercer Mundo, en cambio, comenzaron a restar su apoyo al Movimiento Villero e intentaron recuperar su rol de religiosos en estos barrios populares.

El 13 de marzo de 1974, 400 vecinos, en una Asamblea, resolvieron, entre otras cosas:

Que ningún vecino firme boletos de compra venta de las viviendas de Ciudadela, en tanto no se derogue y se anule el art. 7 de la ley 072-74 Código SEVU; que fija el reajuste de las cuotas mensuales por elevación de los costos de construcción y de acuerdo al salario mínimo vital y móvil que tornaría imposible el pago de las cuotas mensuales [...]

No estamos en contra de que se nos erradique; si estamos dispuestos a luchar para que la fijación de las cuotas de haga con nuestra participación y atendiendo a nuestros intereses y nuestra situación económica actual y futura [...]

No nos moveremos a otro alojamiento, hasta que logremos ser escuchados con nuestros reclamos [...]

No estamos en contra de la erradicación, ni de nuestro gobierno.

Si queremos un diálogo francoy constructivo para ambas partes [...]

El 25 de marzo, la Junta de Delegados y el MVP llamaron a una movilización frente al MBS bajo las consignas: Aqui están, éstos son los villeros de Perón y Queremos casas sin trampas.

En la Plaza de Mayo los esperaban 2000 compañeros y dos diputados de la JP. El saldo fue trágico: en esa ocasión murió el villero $\mathrm{Al}$ berto Chejolán abatido por un disparo de las fuerzas represivas. A partir de aquí, las posibilidades de cualquier diálogo estaban rebasadas. El MVP, en adelante, comenzó a desmembrarse ante la política de hostigamiento generalizado que emprendieron las fuerzas represivas contra los dirigentes villeros. ${ }^{32}$

\section{Epílogo:}

La llegada al gobierno de un partido o fuerza social que exprese cierto grado de compromiso con la defensa de los intereses de las clases populares, provoca inevitablemente un incremento de las expectativas de éstas y, por lo general, un proceso de movilización reivindicativa generalizada. La vuelta del peronismo después de 18 años activó al conjunto de las organizaciones populares que, desde su identificación

32 En mayo de 1974, un grupo de derecha mató al cura villero Carlos Mujica. 
general con la estrategia política del líder y del Movimiento Nacional, hicieron su reaparición en el terreno de la política portando demandas específicas. Los villeros de la ciudad de Buenos Aires, recuperando una década de experiencias organizativas frente a los agresivos planes de erradicación que implementaron los sucesivos gobiernos militares, impulsaron nuevas agrupaciones sectoriales desde las cuales ntentaron legitimar su participación en la gestión estatal y en la escena política global.

Sin embargo, en relación a la cuestión villera, fueron varios los proyectos -en definitiva políticos-que entraron en juego en la coyuntura. El fundamental, en términos del poder para implementarlo que poseían sus portadores, fue el promovido por el MBS. El pequeño grupo de la derecha del Movimiento Peronista que obtuvo esta agencia ministerial, incluyó el problema villero en un programa de vivienda popular global, para el cual el gobierno había asignado un importante monto de recursos. Su efectivización sirvió para reforzar la alianza de este grupo con el empresariado de la industria de la construcción y con la burocracia sindical, mediatizando la participación de los usuarios a quienes se pretendía subordinar. El Plan de las 500000 viviendas tenía garantizado su éxito: contaba con el apoyo de las más altas esferas gubernamentales y, para el caso de las villas, con el aval del general Perón.

La agencia que en el ámbito de la Capital Federal poseía competencia institucional para actuar frente a la cuestión villera, intentó impulsar un proyecto alternativo de relación representantes-representados. El personal de la CMV, contando con una importante experiencia en materia de vivienda popular, impulsó la participación de los usuarios en la gestión gubernamental. La oficina villera y las mesas de trabajo fueron experiencias que -aunque limitadas en su alcance y en particular en cuanto a sus posibilidades de generar prácticas de participación democrática en organismos gubernamentales - fueron embriones de formas de autogestión popular. Sin embargo, este proyecto institucional -como el que en menor escala intentó promover la Universidad de Buenos Aires - se insertaba en el proyecto político de una izquierda peronista que desde los primeros momentos del gobierno popular empezó a sufrir un desplazamiento que terminó en derrota política. El limitado acceso a puestos en el aparato estatal que pudo conseguir fue insuficiente para concretizar sus planteos. Es decir, ni los villeros ni los profesionales progresistas ni los docentes universitarios, pudieron afirmarse en el terreno político para dirimir con eficacia el acierto o error de sus planteos frente a la cuestión de las villas miseria. La lucha ideológica, la identificación del problema con estrategias globales y las cambiantes alternativas de poder que se dieron en 
el interior del Movimiento, así como la definitiva decisión del líder en favor del sector cuyos intereses estaban más distanciados de las aspiraciones villeras, impidieron que el tema de las villas miseria fuese trasladado a un debate abierto. En ningún momento estuvo en discusión la viabilidad de las cooperativas, las empresas populares o la eficacia que habían demostrado tener las mesas de trabajo que funcionaron en la Municipalidad.

La erradicación era presentada como algo natural. Ante la realidad de la ejecución del Plan de las 500000 viviendas, empalidecían las demás reivindicaciones villeras: ¿Qué más podía dar el gobierno popular sino casas a quienes las necesitaban? El reclamo de participación de los villeros, debía ser considerado desde un "concepto peronista", como expresó López Rega. Ello implicaba aceptar el programa verticalmente.

Sin embargo, las organizaciones villeras estuvieron lejos de legitimar las prácticas del $M B S$, a pesar de que contaban con escasos recursos para enfrentarse al poder que el ministro poseía en aquel entonces. El caso del Frente Villero Peronista de Liberación y su acercamiento inicial al MBS, es un indicador de que esta organización no estaba anteponiendo una definición política a las posibilidades de incidir sobre los planes habitacionales y sociales que les incumbían. Fue la derecha peronista la que evidenció rápidamente su manera de concebir el problema villero: el MBS, pretendía ganar reconocimiento entre este sector popular urbano, pero a partir de que éste se subordinara y no mediante la contemplación e incorporación de sus demandas.

El Movimiento Villero Peronista, en cambio, nació como un frente de masas que se identificaba con la estrategia política de la izquierda peronista, la JP y la organización político-militar Montoneros. Esto no demoró el enfrentamiento abierto con el nivel ministerial. La contrapartida fue la posibilidad de que en el interior de la CMV se ensayaran experiencias de participación popular en la gestión gubernamental, a las que ya hicimos referencia. Las posibilidades de que el MVP pudiera influir en la elaboración de una política gubernamental no trascendieron a este aparato municipal, a los de algunos gobiernos provinciales y al intento de la Universidad Nacional de Buenos Aires de apoyar, con proyectos específicos, programas de vivienda popular.

Esto nos lleva a enfatizar en las líneas finales de este trabajo una cuestión que nos parece relevante. El problema de las villas miseria de la Capital Federal se presentaba como una cuestión que albergaba expectativas de poder ser "solucionada" a través de una efectiva acción estatal capaz de representar los intereses populares. No está aquí en juego el análisis de cómo se reproducirían estos barrios populares urbanos u otro tipo de vivienda precaria, sino exclusivamente el enfatizar 
que la magnitud del problema lo tornaba abarcable, sobre todo si se piensa que se contaba con recursos financieros y técnicos. El problema entonces fue exclusivamente político, perdiéndose así la oportunidad de atacar una de las manifestaciones más crudas de la pobreza urbana y transfiriéndose nuevamente su solución en el tiempo.

Pocos años después, la dictadura militar impuesta en 1976 empleó los más crueles métodos de erradicación definitiva de las villas miseria capitalinas. En un clima político de brutal represión, algunos de los pobladores debieron buscar albergue en los municipios de la periferia de la ciudad de Buenos Aires; otros regresaron a sus provincias de origen y los oriundos de los países limítrofes, en su mayoría arraigados desde décadas en Buenos Aires, fueron compulsivamente obligados a retornar a los mismos.

\section{Bibliografía}

"Acta de compromiso nacional": (1973), en Política económica y social: ruptura de la dependencia, 31 de julio, Buenos Aires.

Cámpora, Héctor J.: (1973), "Mensaje ante la Asamblea legislativa el 25 de mayo de 1973" en La revolución peronista, Buenos Aires, EUDEBA.

Comisión Municipal de la Vivienda: (1971), Síntesis de su acción, Buenos Aires.

Comisión Municipal de la Vivienda: (1973a), Informe sobre su creación, desenvolvimiento y tareas realizadas por la CMV (mimeo), diciembre, Buenos Aires.

Comisión Municipal de la Vivienda: (1973b), Participación en la vivienda popular (mimeo), diciembre, Buenos Aires.

De Riz, Liliana: (1981), Retorno y derrumbe: el último gobierno peronista, México, Folios Ediciones.

Landi, Oscar: (1979), "Argentina 1973-76: la génesis de la nueva crisis política" en Revista Mexicana de Sociología, núm. 1, enero marzo, UNAM, México.

Gelbard, José: (1973), "Mensaje del Sr. Ministro de Hacienda y Finanzas, José Gelbard en la 2da. Reunión de Gobernadores del gobierno del pueblo" en Política económica y social: ruptura de la dependencia, Publicación oficial, 31 de julio, Buenos Aires. 
Landi, Óscar: (1979), “Argentina 1973-76: la génesis de la nueva crisis política” en Revista Mexicana de Sociología, núm.1, enero-marzo, UNAM, México.

Ministerio de Bienestar Social, Ministerio del Pueblo: (1973), Un techo para cada uno en el país de todos, Buenos Aires.

Ministerio de Hacienda y Finanzas: (1974), Plan Trienal (1974-1977), Buenos Aires.

Movimiento Nacional Justicialista, Consejo Tecnológico: (1973), Bases para un programa de vivienda. Marco politico y propuestas generales (mimeo), enero, Buenos Aires.

Movimiento Villero Peronista: (s/f), Consideraciones generales del temario político del II Congeso Nacional de MVP, Buenos Aires.

Pastrana, Ernesto: (1980), "Historia de una Villa Miseria en la Ciudad de Buenos Aires (1948-1973)" en Revista Interamericana de Planificación, núm. 54, junio, México.

Portantiero, Juan Carlos: (1980), "Peronismo, socialismo, clase obrera" en Controversia, núm. 8, septiembre, México.

Puiggrós, Adriana: (1979a), "La universidad argentina de 1973-74" (la. parte) en Controversia, núm. 1, octubre, México.

Puiggrós, Adriana: (1979b), "La universidad argentina de 1973-74" (2a. parte) en Controversia, núm. 2/3, diciembre, México.

Saltalamacchia, Rodolfo: (1980), "Capas medias: ideología y política del 60" en Controversia, núm. 9/10, diciembre, México.

Schteingart, M. y B. Broide: (1974), "Procesos sociales, políticas de vivienda y desarrollo metropolitano. El caso de Buenos Aires", en M. Castells: Estructura de clases y política urbana en América Latina, Buenos Aires, Ed. SIAP.

Sociedad Central de Arquitectos: (1976), Boletín, julio, Buenos Aires.

Varios autores: (1982), "Barrio Justo Suárez, relato de una experiencia de participación" en Trama, Revista de Arquitectura, núm. 3, Buenos Aires.

Yujnovsky, Óscar: (1982), Claves políticas del problema habitacional argentino 1955-1981, Buenos Aires, CEUR.

Ziccardi, Alicia: (1977), Políticas de vivienda y movimientos urbanos. El caso de Buenos Aires (1963-1973), Buenos Aires, CEUR. 